\title{
Violência conjugal: problematizando a opressão das mulheres vitimizadas sob olhar de
} gênero ${ }^{1}$

\section{Marital violence: stating the problems of women victims of oppression under a gender view}

\section{Violencia conyugal: problematizando la opresión de las mujeres víctimas en la perspectiva del género}

\author{
Rebeca Nunes Guedes', Ana Tereza Medeiros Cavalcanti da Silva", Edméia de Almeida Cardoso \\ Coelho"l'
}

\section{RESUMO}

Estudo realizado com a finalidade de ampliar a compreensão da violência conjugal, no qual buscou-se compreender o significado do fenômeno para as mulheres que a sofrem. A produção do material qualitativo da investigação foi conseguida por meio de entrevistas realizadas com mulheres em situação de violência e de denúncia na Delegacia da Mulher em de J oão Pessoa-PB, no ano de 2006, cujos discursos foram analisados segundo a perspectiva de Fiorin ${ }^{8}$. A análise dos discursos evidenciou que a violência conjugal é um modo de manifestação da assimetria de poder presente nas relações de gênero; que há o reconhecimento das mulheres do poder masculino sobre elas, refletido pelo temor e pela subordinação na relação conjugal em que ocorre a violência e que esse domínio corresponde a uma espécie de tutela construída e legitimada pela cultura patriarcal e machista, necessária, no pressuposto do idealismo positivista da ideologia dominante, para administrar os excessos de paixões que fariam parte da imperfeição da natureza feminina.

Palavras-chave: Violência contra a mulher; Gênero e saúde; Identidade de gênero; Poder.

\section{ABSTRACT}

This study is intended to enlarge the understanding of marital violence. The research investigated what marital violence does mean to women victims of this kind of violence. The results of the qualitative material in this research were achieved through interviews with women in situation of reported violence in the Women Police Station in João Pessoa-PB in 2006, whose speeches were analyzed under the perspective of Fiorin ${ }^{8}$ The analysis of the speeches showed that marital violence is a manifestation of the power asimmetry present in the relation of the genders; the recognition by women of men's power over them evidenced by fear and subordination in the marital relationship where violence occurs and that such control represents a kind of tutelage built and legitimized by the patriarchal and male chauvinist culture which is necessary in the positivist idealism of the dominant ideology to manage the excessive passion which is part of the female nature.

Key words: Violence against women; Gender and health; Gender identity; Power.

\section{RESUMEN}

El presente estudio tiene la finalidad de ampliar la comprensión de la violencia conyugal. Buscamos entender el significado del problema para las mujeres que la sufren. La producción del material empírico cualitativo de la investigación fue obtenida por medio de

\footnotetext{
1 Artigo originado a partir da dissertação de mestrado: Guedes RN. Violência conjugal: problematizando a opressão das mulheres vitimizadas sob olhar de gênero. [Dissertação] J oão Pessoa (PB) PPGEnf/CCS/ Universidade Federal da Paraíba; 2006.

'Enfermeira. Mestre pelo Programa de Pós-Graduação em Enfermagem da Universidade Federal da Paraíba, João Pessoa- PB. E-mail- rebecanunesguedes@gmail.com

II Enfermeira, Professora Doutora em Enfermagem pela Escola de Enfermagem da USP. Professora Adjunto do Departamento de Enfermagem Em Saúde Pública e Psiquiátrica do Centro de Ciências Sociais da Universidade Federal da Paraíba - UFPB. Coordenadora do Grupo de Estudos sobre Saúde e Sociedade ligado ao Programa de Pós-Graduação em Enfermagem da UFPB. E-mail anatmc8@yahoo.com.br

III Enfermeira. Doutora em Enfermagem pela Escola de Enfermagem da USP. Professora Adjunta do Departamento de Enfermagem Comunitária da Escola de Enfermagem da Universidade Federal da Bahia (UFBA)-coordenadora do estudo. Pesquisadora do Grupo de Estudos sobre Saúde da Mulher (GEM) da Escola de Enfermagem da UFBA. E-mail edmeiacoelho@yahoo.com.br.
} 
Guedes RN, Silva ATMC, Coelho EAC. Violência conjugal: problematizando a opressão das mulheres vitimizadas sob olhar de gênero . Revista Eletrônica de Enfermagem [serial on line] 2007 Mai-Ago; 9(2): 362-378. Available from: URL: http://www.fen.ufg. br/revista/v9/n2/v9n2a06.htm

entrevistas con las mujeres en la situación de la violencia y de la denuncia en la Comisaría de Policía de la Mujer en João Pessoa - PB, en 2006. Sus discursos fueron analizados según la perspectiva de Fiorin. El análisis de los discursos evidenció que la violencia conyugal es una manera de la manifestación de la asimetría de el poder, presente en las relaciones de la clase; que tiene el reconocimiento de las mujeres de el poder masculino en ellas, reflejadas para el miedo y la subordinación en la relación conyugal donde

\section{NTRODUÇÃO}

A violência vem sendo considerada, pela OMS, um dos maiores problemas de saúde pública em todo o mundo. Pesquisas realizadas em diversos países revelam que a violência conjugal tem sido uma das maiores causas de morbidade em mulheres, afetando significativamente sua saúde, representando, também, perdas potenciais no campo do desenvolvimento pessoal, social, afetivo e econômico ${ }^{(1)}$. Cerca de metade das mulheres latino-americanas é vítima de alguma violência, porém, ao contrário da situação enfrentada pelos homens, que na maioria das vezes são agredidos por pessoas distantes do seu meio familiar e no espaço público, a violência contra a mulher ocorre principalmente no espaço doméstico e é exercida por parceiros ou outras pessoas com quem as vítimas mantêm relações afetivas ou íntimas ${ }^{(2)}$.

Desse modo, a violência, quando praticada contra a mulher, por ser uma questão de gênero, assume um diferente enfoque, uma vez que, na grande maioria dos casos, o agressor é alguém do sexo masculino, seu parceiro ou cônjuge. Sendo assim, a violência contra a mulher é resultado de relações de poder construídas ao longo da história pela desigualdade de gênero e ocurre la violencia y que este dominio corresponde a una especie de la tutela construida y legitimada por la cultura patriarcal y machista, necesaria, en estimada del idealismo positivista de la ideología dominante, para manejar los excesos de las pasiones que serían parte de la imperfección de la naturaleza femenina.

Palabras clave: Violencia contra la mujer; Género y salud; Identidad de género; Poder.

consolidadas por uma ideologia patriarcal e machista.

As relações existentes entre os cônjuges são regidas por papéis sociais (mãe-mulherdona de casa e pai-marido-chefe de família), construídos ideologicamente como cultura, nos quais estão implícitas as desigualdades de gênero, fortemente introjetadas no imaginário social, sendo sua naturalização um dos fatores de opressão para as mulheres e de aceitação no imaginário social do senso comum $^{(3)}$. Essa forma de violência implica agravos à saúde física e mental das mulheres, limitando sua capacidade produtiva e prejudicando sua qualidade de vida e auto-estima. O fenômeno constitui uma contradição que precisa ser identificada, compreendida e enfrentada no enfoque das relações de gênero para que as mulheres possam desfrutar das condições sociais de igualdade, pressupostas nos ideários da civilização ocidental, desde a modernidade, para todos os seres humanos ${ }^{(4)}$.

Ainda que a violência contra a mulher venha ganhando visibilidade social é reconhecida a necessidade de aprofundarmos a compreensão a respeito da complexidade desse problema, para desenvolvermos mecanismos para seu enfrentamento. Por ser uma questão que envolve tabu, aspectos morais, sociais e 
Guedes RN, Silva ATMC, Coelho EAC. Violência conjugal: problematizando a opressão das mulheres vitimizadas sob olhar de gênero. Revista Eletrônica de Enfermagem [serial on line] 2007 Mai-Ago; 9(2): 362-378. Available from: URL: http://www. fen.ufg. br/revista/v9/n2/v9n2a06. htm

ideológicos, a vítima da violência conjugal, em geral, convive com o isolamento social e o silêncio, impostos por mecanismos psicológicos de defesa diante da violência, contra sentimentos de fragilidade e impotência diante do abuso de força física e psicológica pelo parceiro masculino ${ }^{(4)}$.

Muitas vezes, essas vítimas não entendem os comportamentos violentos como tais, mas, como algo "natural" e incapaz de ser mudado, aceitando como destino a submissão, a desigualdade e a exclusão social. Os efeitos relacionados com o trauma decorrente da situação de violência na vida e na saúde das mulheres são exacerbados pelo fato de o agressor ser alguém de sua intimidade, com quem divide uma relação permeada por sentimentos afetivos, o que eleva a sensação de perda, vulnerabilidade, traição e desesperança ${ }^{(5,6)}$.

Desse modo, conhecer como as vítimas concebem esse fenômeno e como ele afeta sua vida, possibilitará a identificação de caminhos que levem ao enfrentamento e superação das contradições que alimentam a desigualdade de gênero e permitem o desenvolvimento da violência conjugal praticada contra as mulheres. Os profissionais de saúde, particularmente os que atuam no âmbito da saúde pública, trabalham muito tempo em contato com a comunidade e com os problemas vividos por ela sendo essa particularidade, fator que contribui para o desenvolvimento de estratégias no sentido de prevenir, enfrentar, e/ou amenizar problemas ${ }^{(7)}$.

Sendo assim, ampliar investigações e aprofundar a discussão sobre esse fenômeno da realidade possibilitará uma melhor compreensão e visibilidade do problema, além de oferecer subsídios para que políticas públicas e a atuação dos profissionais nos Serviços de Saúde valorizem estratégias para o empoderamento das mulheres, possibilitando, assim, rupturas das amarras da submissão.

Nesse sentido, este estudo parte de uma aproximação com as mulheres vitimizadas, de modo a conhecer sua convivência com esse tipo de opressão masculina e tem como objetivo compreender o significado da violência conjugal, segundo a concepção das mulheres que a sofrem.

\section{MÉTODOS}

Pesquisa de abordagem qualitativa cujos elementos do objeto de estudo foram analisados a partir da perspectiva de gênero. Isso significa que a leitura feita sob esse objeto teve como enfoque principal a construção histórica das relações sociais entre os sexos, bem como, o modo como a ideologia de gênero influencia os discursos a respeito da violência conjugal vivenciada pelas participantes do presente estudo. Visando aprofundar o conhecimento acerca do fenômeno, buscamos compreender o significado que a violência conjugal assume para as mulheres vitimizadas, a partir dos depoimentos de mulheres que sofreram alguma forma de violência conjugal e a denunciaram,

O estudo foi realizado no município de João Pessoa - PB, na Delegacia Especializada de Atendimento à Mulher (DEAM), durante o período de 20 de fevereiro a 24 de maio de 2006.

Para a produção do material empírico, foram consideradas as mulheres em situação de violência conjugal, no momento em que realizavam a denúncia. As mulheres 
Guedes RN, Silva ATMC, Coelho EAC. Violência conjugal: problematizando a opressão das mulheres vitimizadas sob olhar de gênero. Revista Eletrônica de Enfermagem [serial on line] 2007 Mai-Ago; 9(2): 362-378. Available from: URL: http://www.fen.ufg.br/revista/v9/n2/v9n2a06. htm

entrevistadas foram aquelas que, durante os meses de abril e maio de 2006, estiveram na DEAM em situação de denúncia contra violência conjugal e apresentaram interesse em participar do estudo, assim como disponibilidade de tempo e estado emocional que permitisse a realização do processo de entrevista.

Os depoimentos foram gravados em fitas cassete e, logo após cada entrevista, eram transcritas, em sua íntegra, acompanhadas de observações sobre os diferentes momentos da entrevista. Após cada transcrição, procedemos a pelo menos duas leituras de cada texto, marcando os principais temas $e$ as recorrências, as repetições, as redundâncias mais evidentes. Posteriormente, no processo de análise mais aprofundado, essas marcações serviram de guia para desvelar posições sociais, apresentadas pelas mulheres, que ofereciam possibilidades de revelar visões de mundo, valores e sentimentos capazes de expressar o fenômeno em sua magnitude por aquelas mulheres frente aos objetivos da pesquisa. Desse modo, ao completar oito entrevistas, observamos que 0 material permitia analisar o fenômeno recortado, razão pela qual a coleta foi encerrada. Os encontros foram norteados por um roteiro de entrevista comum para todas as mulheres, aplicado de uma maneira flexível, que, muitas vezes, tomava a forma de uma conversa informal, atendendo à singularidade de cada mulher na sua trajetória de vida.

Este estudo atendeu aos requisitos propostos pela Resolução 196/96 do Conselho Nacional de Pesquisa que dispõe sobre as normas e diretrizes regulamentadoras da pesquisa envolvendo os seres humanos. Após aprovação do projeto de pesquisa pelo Comitê de Ética e Pesquisa do CCS-UFPB sob protocolo 261/06, iniciamos a investigação junto à Delegacia da Mulher. Desse modo, mantivemos o contato com algumas denunciantes para explicar-lhes os objetivos da pesquisa e esclarecer-lhes os aspectos éticos dispostos no Termo de Consentimento Livre e Esclarecido. Após conseguir seu consentimento em participar do estudo, com a sua assinatura do documento, foi iniciado o processo de entrevista, tendo sido solicitado a cada mulher escolher um nome fictício a ser utilizado na pesquisa, de forma a garantir seu anonimato.

A análise do material empírico foi iniciada com a transcrição do material produzido pelas entrevistas, impressão e leitura dos textos. Subseqüentemente, passamos à re-leituras dos textos e à identificação dos temas sob o enfoque de gênero. Em seguida, foi feito o recorte dos textos que continham os temas que orientaram a construção das sub-categorias, considerando o objeto e os objetivos deste estudo. Em todo o processo de análise e discussão, o material empírico foi relacionado com a literatura pertinente, para ancorar as posições sociais nele reveladas, conforme a orientação para a análise do discurso na perspectiva proposta por Fiorin ${ }^{(8)}$.

O princípio básico desse enfoque é a compreensão de que o discurso é uma posição social devendo, assim, ser analisada. Segundo o autor, os textos são analisados, não para se responsabilizar individualmente as pessoas, mas para se identificarem determinadas posições sociais que se manifestam discursivamente no interior da sociedade, marcadas pela ideologia, de modo que “enquanto o discurso é a materialização das 
Guedes RN, Silva ATMC, Coelho EAC. Violência conjugal: problematizando a opressão das mulheres vitimizadas sob olhar de gênero. Revista Eletrônica de Enfermagem [serial on line] 2007 Mai-Ago; 9(2): 362-378. Available from: URL: http://www.fen.ufg. br/revista/v9/n2/v9n2a06.htm

formações ideológicas, sendo por isso determinado por elas, o texto é unicamente o lugar de manipulação consciente, em que o homem organiza, da melhor maneira possível, os elementos de expressão que estão à sua disposição para veicular seu discurso. O texto é, pois, individual, enquanto o discurso é social" (8).

Para percebermos a reiteração, segundo essa técnica, agrupamos os elementos significativos, as figuras ou os temas que se confirmavam num mesmo plano de significado, na seqüência percorremos o texto inteiro numa tentativa de localizar todas as recorrências, isto é, todas as figuras e temas que conduzem a um mesmo bloco de significação. A identificação/rejeição dos sujeitos discursistas com os diversos temas por eles referidos informa seus valores, crenças, anseios e expectativas (dos sujeitos discursistas) que revelam a visão de mundo do enunciador. Desse modo, o texto pode ser compreendido como um tecido no qual procuramos a organização dos seus fios, suas tramas, ou seja, o arranjo que lhes confere significado na malha social.

Seguindo essa orientação metodológica de análise, identificamos os temas emergentes dos discursos que permitiam a organização dos blocos de significação que orientaram a construção das seguintes subcategorias empíricas: A assimetria de poder impondo submissão e silêncio das mulheres em situação de violência; O duplo da violência: dominação e possibilidade de desconstrução do modo idealizado hegemonicamente de casamento; A visibilidade do impacto da violência na vida biológica, psicológica e social das mulheres vitimizadas. Ao término dessa etapa do processo, verificamos que as subcategorias poderiam ser acolhidas em um grande conceito ou categoria maior denominada: A violência conjugal e sua relação com a tutela da diferença nas relações desiguais de gênero.

Visando atender o objetivo proposto para este artigo, passaremos à apresentação da primeira subcategoria empírica, construída a partir dos temas e discursos revelados nos depoimentos das participantes, que dizem respeito à sua compreensão das mulheres vitimizadas acerca da violência conjugal vivenciada.

\section{RESULTADOS E DISCUSSÃO}

Considerando que o recorte do fenômeno comporta a incursão nos dois níveis de experiência do social, aquele que se revela quantitativamente em percentuais e o que se revela qualitativamente em significados, apresentamos o perfil sócio-demográfico das mulheres, sujeitos da investigação. Tais sujeitos da pesquisa se encontravam em situação de violência por ocasião da investigação e prestando denúncia contra seus agressores. A elas foram atribuídos os seguintes nomes fictícios: Atena, Márcia, Rosa, Vitória, Socorro, Suelen, Priscila e Rosália:

- A I dade variou entre 21 e 41 anos.

- Em relação ao estado civil, cinco eram solteiras, duas casadas e uma divorciada.

- Apenas uma não possuía filhos, tendo as demais uma média de dois filhos, variando de uma a cinco.

- A religião de cinco das participantes era a católica, sendo uma espírita e duas sem religião definida. 
- Em relação à escolaridade, uma participante tinha o ensino superior concluído, duas concluíram o ensino médio, uma tinha o ensino médio incompleto, três o ensino fundamental incompleto e uma se declarou analfabeta.

- Em relação à profissão das participantes apontamos: uma comerciante, uma professora, uma cabeleireira, uma doméstica, uma vendedora ambulante, uma auxiliar operacional e duas do lar. Em relação ao parentesco com os agressores, foram identificados: dois companheiros, um cônjuge, quatro ex-companheiros e um ex-cônjuge.

- Os motivos que levaram as participantes à delegacia da mulher, foram: agressão física, agressão moral e ameaça; agressão física, agressão moral e solicitação de pensão, perseguição; agressão física e efeito de separação; agressão física e perseguição; e agressão física, destacando-se que, todas as participantes, em seus depoimentos, relataram história de violência física e/ou psicológica, por parte dos parceiros ou ex-parceiros.

Subseqüentemente, aprofundaremos a análise dos significados que se refere à interpretação dos sentidos que o objeto de estudo assume como qualidade, sintetizado na Categoria e subcategoria correspondente.

\section{A violência conjugal e sua relação com a tutela da diferença nas relações desiguais} de gênero : a assimetria de poder impondo a submissão e o silêncio das mulheres em situação de violência.

A desigualdade de gênero ficou evidente nos depoimentos das mulheres que participaram do estudo, cujos discursos ao serem sintetizados na subcategoria: A assimetria de poder impondo a submissão e o silêncio das mulheres em situação de violência, mostram que o desequilíbrio do poder em favor do homem caracteriza a desigualdade de gênero. Essa assimetria do poder nas relações conjugais decorre de outras desigualdades que ocorrem na sociedade mais ampla, determinadas por práticas sociais que manifestam uma irregularidade ou deformação na qualidade de valores incompatíveis com o ideário humanista anunciado na modernidade, como a que se manifesta na ideologia capitalista a partir da desigualdade entre capital e trabalho, lugar social de intersecção do eixo sócio-econômico e do eixo cultural, que promove a desigualdade e a exclusão nessas sociedades.

Nesse contexto, o poder se apresenta como um privilégio do universo masculino e como tal é algo que não pode ser ampliado para o universo feminino, sem deixar de ser privilégio. Os privilégios estão entre as categorias que contrariam o principio democrático de igualdade porque contradiz os direitos universais pressupostos no significado do conceito de democracia, mas os privilégios se mantêm e se reproduzem, na atualidade, para atender ao precipício liberal e neoliberal hegemônicos da igualdade apenas formal. Esta confunde a diferença com a desigualdade, considerando-as uma inferioridade natural e por meio da ideologia é possível estabelecer as relações sociais verticais norteadas pela idéia 
Guedes RN, Silva ATMC, Coelho EAC. Violência conjugal: problematizando a opressão das mulheres vitimizadas sob olhar de gênero. Revista Eletrônica de Enfermagem [serial on line] 2007 Mai-Ago; 9(2): 362-378. Available from: URL: http://www.fen.ufg.br/revista/v9/n2/v9n2a06. htm

de mando, obediência e subordinação do patriarcalismo. Essas condições sociais tornamse o solo fértil para a naturalização das desigualdades inclusive a de gênero e de todas as formas visíveis e invisíveis de violência.

Estruturada a partir das relações familiares essas relações sociais patriarcais fomentam o impedimento da visibilidade das contradições sociais, pois, a naturalização das desigualdades e da violência em todas as suas manifestações faz parecer uma imagem de sociedade ordeira, o que significa que os movimentos sociais e populares por igualdade na diversidade passam a ser explicados pela hegemonia como caos social, desordem e perigo.

Assim, as relações entre os sexos, tanto no espaço privado do lar conjugal, quanto no espaço público das relações civis, são caracterizadas por uma relação assimétrica de poder, na qual a desigualdade e a exclusão do poder para as mulheres manifesta-se e é explicada pelas diferenças físicas, sexuais e biológicas, justificando-se a "natureza" da sujeição feminina. A construção sócio-cultural da identidade feminina e a definição de seus papéis como figura passiva e submissa cria o espaço propício para o exercício da opressão masculina sobre as mulheres que permitem a violência conforme os discursos que se apresentam nos textos a seguir:

[...] Eu não vi que ele tava lá dentro de casa. Quando ele levantou-se, fez: 'O que foi que você disse?' Ai eu tremi na hora ...e disse: 'Você está escutando demais' ai ele disse: 'Diga de novo pra eu quebrar sua cara'. Ai eu vi que ele estava nervoso e entrei [...]. (Rosália).
Minha cabeça era assim: ele dava em mim e eu baixava o cangote. Ele dava em mim em cima da cama, dava em mim sentada. Eu me sentava pra apanhar [...] Eu já apanhei tanto num barraco de tábua, ficava caída no chão. (Socorro).

Eu tinha que me esconder com os meus meninos dentro do guarda-roupa ou então debaixo da cama. (Rosália).

Nesses depoimentos, podemos observar o reconhecimento das mulheres do poder que seu parceiro exerce sobre elas. Esse reconhecimento manifesta-se no temor que o discurso revela. $O$ medo e a submissão feminina ao parceiro são temas determinados pelo ideal da superioridade "natural" masculina, decorrente da maior força física que reveste o homem, inclusive, do poder total sobre a vida e morte da mulher. Esse medo tem conseqüências psicológicas sobre a sua auto-estima e influencia a saúde mental das mulheres em situação de violência, porque ameaça a sua vida. Nesse sentido, o depoimento seguinte atesta as bases de posse sobre a pessoa, que caracteriza o patriarcado e a força de dominação masculina sobre a mulher.

[...] ele entrou atrás de mim, puxou meus cabelos e disse: 'Diga de novo o que você disse lá fora que eu te boto sete palmos debaixo da terra. (Rosália).

O enfoque do patriarcalismo pressupõe a tutela masculina sobre 0 universo das mulheres, pressuposto incompatível com a idéia de liberdade e de igualdade entre os seres humanos. Essa é a maior contradição, uma contradição interna que interdita o enfoque dialético nas relações conjugais porque a subordinação de um dos pares do 
Guedes RN, Silva ATMC, Coelho EAC. Violência conjugal: problematizando a opressão das mulheres vitimizadas sob olhar de gênero. Revista Eletrônica de Enfermagem [serial on line] 2007 Mai-Ago; 9(2): 362-378. Available from: URL: http://www.fen.ufg.br/revista/v9/n2/v9n2a06. htm

contrato de casamento imprime assimetria e enfoque paternalista à relação, pois as mulheres estão sujeitas aos consentimentos e não podem determinar sua liberdade nem sua autonomia de ser humano igual na diferença entre os sexos, sem desencadear mecanismos de repressão por violência física e/ou psicológica.

Historicamente, o paternalismo tem sido uma categoria sociológica de análise que se opõe à igualdade porque fomenta privilégios para uma das partes envolvidas no contrato social e conseqüentes perdas nos espaços civis e do direito de cidadania das mulheres.

Podemos aqui considerar o fato de que teóricos do contrato social apoiaram-se na idéia de que as mulheres não podem ser incorporadas à sociedade civil por não possuírem os atributos necessários para se tornarem indivíduos civis, porém, eles não explicam que atributos são esses. A explicação predominante limita-se à referência à maior força física, mental ou à capacidade superior masculina ${ }^{(9)}$.

No enfoque crítico sobre a gênese da humanidade dos seres humanos, o ser humano biológico 'natural' torna-se humano por meio de seu vínculo com a dimensão social do existir e pela história das relações sociais no processo de vida de cada um. Assim, a abordagem da "natureza feminina" de submissão valoriza apenas a dimensão do ser animal e desconsidera a vida de relações sociais, ou seja, nega-se a mulher como ser humano complexo, cuja unidade realiza-se na atividade psíquica individual, embora essa atividade seja qualitativamente diferente dos aspectos biológicos e sociais, pois resulta da síntese de vários universos de significado com os quais homens e mulheres se relacionam ${ }^{(10)}$.

Desse modo, observamos que há uma explicação, embora não a única, para a dominação masculina sobre a mulher, que tem origem na formação da sociedade civil, quando a força física era o instrumento de dominação por excelência. Na modernidade, além da força física, os homens recorrem a outros instrumentos para manter a submissão feminina, como a ideologia burguesa defendida por Comte ${ }^{(11)}$ como exemplo para a dominação dos proletários pela burguesia, quando ele afirma que: "graças ao positivismo os proletários reconhecerão com a ajuda feminina as vantagens da submissão e de uma digna irresponsabilidade" (11). Para esse autor, a mulher é naturalmente submissa e irresponsável e isso não the parece desabonador, pelo contrário.

O processo de construção cultural da desigualdade de gênero ao longo da historia é introjetado por homens e mulheres, de modo que às mulheres foi imposta a sujeição na relação que reconhece, na sua pouca força física uma inferioridade "natural", conforme a declaração abaixo:

Eu busquei a justiça porque eu me senti impotente em relação a ele, porque eu não ia chegar, bater, porque, você sabe que, por mais que uma mulher seja forte, ela não é páreo para um homem. O homem tem uma desenvoltura melhor. (Vitória).

Eu não agüento mais, porque vai chegar um dia...que eu não tenho a força que ele tem, então é isso que eu quero, que ele resolva se ele vai viver ou não vai. Se ele quer, ele tem que assinar um papel, que se acontecer algo ele seja responsável...porque se eu digo que 
Guedes RN, Silva ATMC, Coelho EAC. Violência conjugal: problematizando a opressão das mulheres vitimizadas sob olhar de gênero . Revista Eletrônica de Enfermagem [serial on line] 2007 Mai-Ago; 9(2): 362-378. Available from: URL: http://www.fen.ufg. br/revista/v9/n2/v9n2a06. htm

não quero mais ver ele diz: 'Vou tocar fogo na casa, vou lhe matar.(Rosa).

[...] A polícia é quem tem que tomar as providências, me dar segurança de vida, dar um despejo dele pra ele sair da minha casa. É isso que eu quero, que isso faça com que tema ele a alguma coisa, porque se isso não temer a ele , aí, pronto, é o jeito eu sumir do mapa.(Rosa)

Esse domínio masculino nas relações de gênero também ainda corresponde a uma espécie de tutela que tem base na legitimação da cultura machista, alicerçada em uma lógica de dominação de uma "natureza" feminina que não teria competência para se autodeterminar, requerendo uma gestão masculina capaz de administrar os excessos das paixões femininas.

Os depoimentos que seguem revelam a gestão masculina da vida material e emocional feminina através da desconfiança e do controle excessivo dos homens em relação à sua mulher, fator desencadeante da violência e opressão feminina, traduzido nos discursos que os depoimentos revelam como negação do direito á vida e à liberdade, direitos fundamentais de todos os seres humanos.

[...] vive desconfiando, vive dizendo que eu vivo com um, que eu vivo com outro. Eu não posso ter um celular, eu não posso ter nada, eu não posso falar com ninguém, eu não posso pisar numa calçada,[...] Eu não tenho colega porque ele não deixa ninguém ir à minha casa, ele não deixa, tudo ele vê visagem na cabeça dele, diz que eu vivo traindo ele e eu acho que isso não é vida [...]. Hoje eu sei que pra pessoa viver dentro de uma cadeia, não é preciso roubar, nem matar, nem fazer nada de errado não porque eu me sinto prisioneira, eu me sinto dentro de uma cadeia. (Rosa).
Peguei meu menino, fui dar uma andadinha no parque e, de lá, eu fui na casa do meu irmão. Quando eu cheguei no portão, ele foi e deu uma tapa na minha cara, perguntando onde eu estava, que queria saber com quem eu estava.( Márcia).

Ele me mandava embora de casa toda hora, me chantageava, dizia que eu tinha outras pessoas e eu vivia de casa pra o trabalho, do trabalho pra casa, quando eu trabalhava, né? Quando eu estava no trabalho, ele ia me vigiar, sendo que ele era uma pessoa imprestável. Tudo que ele pensava que eu poderia fazer, quem fazia era ele. (Atena).

A construção sócio-cultural do universo feminino submisso legitimou, por muito tempo, a imagem negativa da imperfeição presente nas mulheres. Podemos, aqui, referir-nos ao mito da caixa de Pandora e à passagem bíblica do Gênesis, que se referem à mulher com a sua curiosidade incontrolável como causadora de todos os males presentes ma humanidade e como fundadora do pecado no mundo, antes perfeito. Mesmo após a histerização do corpo feminino, que transforma a mulher, de louca e insaciável em um ser desprovido de prazer e desejo, voltado apenas para a procriação(12), ainda permanece, na sociedade atual o medo da sexualidade feminina, traduzido aqui pelo medo da infidelidade feminina pelo parceiro, que, muitas vezes, como revelou Atena em seu discurso, temem que a mulher reproduza um comportamento praticado por ele.

A naturalização e a oficialização da desigualdade de gênero têm sido historicamente produzidas constituindo um instrumento que legitima a dominação masculina, uma vez que, sendo "natural" é social e culturalmente reconhecida. Ao longo 
Guedes RN, Silva ATMC, Coelho EAC. Violência conjugal: problematizando a opressão das mulheres vitimizadas sob olhar de gênero. Revista Eletrônica de Enfermagem [serial on line] 2007 Mai-Ago; 9(2): 362-378. Available from: URL: http://www.fen.ufg. br/revista/v9/n2/v9n2a06.htm

dos séculos, a idéia da mulher como sexo fraco e submisso e a referência à periculosidade feminina, portanto desvalorizada, acompanham a imagem da mulher. A associação da sexualidade feminina como transgressão ainda hoje tem profundos efeitos na configuração do campo da saúde e da violência ${ }^{(13)}$.

O contrato de casamento também é compreendido como uma relação de trabalho, na qual, em troca do sustento e proteção o marido recebe da esposa o trabalho doméstico e o acesso sexual ao seu corpo. No contrato de casamento, o marido detém a propriedade da pessoa de sua esposa, tendo o direito de fazer - que quiser com sua propriedade, não dispondo apenas do acesso a seu trabalho e ao seu corpo, mas também aos seus sentimentos e ao seu ser como um todo, como um objeto ${ }^{(9)}$. Esse poder total do marido não só sobre o corpo, mas, também, sobre a vontade da mulher é revelado no depoimento de Rosália.

[...] aí quando foi uma noite ele decidiu fazer sexo comigo e eu saí correndo e ele correndo atrás de mim. Quando eu vi que ele estava altamente agressivo ai eu parei e disse: 'Faça eu estou aqui[...] ' e fui obrigada a fazer! (Rosália).

O discurso veiculado no depoimento acima revela que o argumento de que 0 casamento permite o desfrute sexual igualitário e consensual entre os esposos é uma inverdade, pois o marido é suficientemente forte fisicamente e simbolicamente e tem a aprovação da opinião pública e da legislação para forçar sua esposa a se submeter a ele, queira ela ou não. Fortalecendo essa idéia, podemos citar como exemplo, a legislação de muitas sociedades que sancionam, ou, até pouco tempo atrás, sancionavam o estupro conjugal, que também ainda é silenciado e não percebido como tal, no interior de muitas relações conjugais ${ }^{(14)}$.

O exame da construção de gênero ao longo da história mostra que as mulheres foram, em nossa trajetória histórica e social, politicamente excluídas do mundo público, sendo atribuído ao mundo privado do lar o lócus destinado a elas, onde administram os cuidados com o marido, com os filhos e realizam o trabalho doméstico, considerado seu principal atributo Estar circunscrito a esse espaço é estar privado da relação com os outros pela palavra e pela ação na construção das decisões concernentes ao mundo público, ou seja, à existência política.

Marilena Chauí (12) define a violência como um constrangimento que faz com que certa realidade opere contra sua natureza, porém, a autora afirma que nada impede que se conceba a natureza das coisas e das pessoas de uma maneira que seja possível exercer violência sobre elas, sem necessariamente supor que isso esteja ocorrendo. Em outras palavras, nada impediu que concebêssemos a natureza feminina de maneira que circunscrevesse as mulheres, seus sentimentos, pensamentos e ações à esfera privada do mundo doméstico e da procriação.

Ao serem excluídas da participação na vida social e política, foi negada às mulheres a oportunidade de adquirir autonomia e independência financeira, sendo o casamento, por muito tempo, a única oportunidade que as mulheres tinham de adquirir segurança financeira e de se firmarem como seres que obedecem às exigências sociais da mulher casada, mãe e dona de casa, papéis sociais que também são incorporados pelas mulheres, 
Guedes RN, Silva ATMC, Coelho EAC. Violência conjugal: problematizando a opressão das mulheres vitimizadas sob olhar de gênero. Revista Eletrônica de Enfermagem [serial on line] 2007 Mai-Ago; 9(2): 362-378. Available from: URL: http://www.fen.ufg. br/revista/v9/n2/v9n2a06.htm

fazendo parte de seu ideal. "As mulheres foram forçadas a participar desse suposto contrato. Os costumes sociais destituíram as mulheres da oportunidade de ganharem seu próprio sustento, de modo que o casamento era a única chance de elas construírem uma vida decente. O 'contrato' de casamento era exatamente como o contrato que os senhores de escravos das Índias Ocidentais impunham aos seus escravos; o casamento não era nada mais que a lei do mais forte, aplicada pelos homens em detrimento do interesse das mulheres, mais fracas" ${ }^{(9)}$.

O princípio da exclusão que respalda o sexismo assenta na distinção entre o espaço público e o privado e no princípio da integração desigual, no papel da mulher na reprodução do trabalho doméstico e, mais tarde, na integração e formas desvalorizadas da força de trabalho(15).

O contrato de trabalho foi definido, depois da revolução burguesa, como um contrato entre duas partes livres e iguais ${ }^{(9,15)}$, porém sabemos que, nesse contrato, uma das partes torna-se "voluntariamente" subordinada. No que concerne às mulheres, elas já são "naturalmente" subordinadas, não tendo as habilidades "naturais" necessárias para participar de contratos, a não ser o de casamento que legitima sua sujeição na sociedade civil. Sendo assim "o sistema da desigualdade assenta paradoxalmente no essencialismo da igualdade, sendo, por isso, que o contrato de trabalho é um contrato entre partes livres e iguais, e o sistema de exclusão assenta no essencialismo da diferença, seja ele a cientifização da normalidade e, portanto, do interdito, ou o determinismo biológico da desigualdade racial ou sexual" (15).
À medida que os direitos de cidadania foram sendo conferidos às mulheres e elas ingressaram no mercado de trabalho, elas foram passando do sistema de exclusão para o de desigualdade, ou seja, elas foram integradas pelo trabalho, no mundo público, mas os seus salários continuaram, até o presente, a ser inferiores aos dos homens ${ }^{(3,15)}$. No espaço mais amplo da vida social, as diferenças são convertidas em desigualdades, que se transformam em relações de subordinação que possibilita as situações de violência ${ }^{(12)}$.

Em decorrência das conquistas das mulheres ampliando seu espaço no mundo público do trabalho, e sendo o trabalho remunerado uma realidade na vida de muitas mulheres, a permanente força do ideal da "dona de casa" permanece como tributo do contrato sexual ${ }^{(9)}$. Contudo, o ingresso no mercado de trabalho não diminuiu a responsabilização social das mulheres pelos cuidados com o lar e a família, o que tem como resultado a dupla ou tripla jornada de trabalho, gerando desgaste e sobrecarga e constituindo mais um fator de opressão. Isso resulta muitas vezes na supressão de outras formas de sociabilidade e formas de ser no mundo em sua dimensão coletiva e singular, que são tão necessárias à vida do ser humano. ${ }^{(16)}$

\section{Após terem conquistado maiores espaços} capazes de possibilitar às mulheres melhores qualificações educacionais e habilidades profissionais, foi-lhes possível ingressar, de modo satisfatório, no mercado de trabalho, ampliando, para muitas mulheres, a possibilidade de se sustentar. Contudo, a observação do cotidiano revela que poucas mulheres ocupam posições bem remuneradas 
Guedes RN, Silva ATMC, Coelho EAC. Violência conjugal: problematizando a opressão das mulheres vitimizadas sob olhar de gênero . Revista Eletrônica de Enfermagem [serial on line] 2007 Mai-Ago; 9(2): 362-378. Available from: URL: http://www.fen.ufg.br/revista/v9/n2/v9n2a06.htm

no mercado de trabalho, recebendo salários muito inferiores ao salário dos homens, na mesma posição, sendo, na maioria das vezes, dirigidas por eles, o que demonstra ser o mercado capitalista patriarcal e estruturado também pela divisão sexual do trabalho ${ }^{(17)}$.

Apesar da desigualdade de gênero que permeia a vida das mulheres, mesmo quando elas conquistam espaço no mercado de trabalho, algumas das mulheres, participantes deste estudo, revelaram o trabalho remunerado e a independência financeira como condição de transformação e de libertação das amarras da violência na vida conjugal.

Aí eu não agüentei mais e deixei, ai eu disse 'não, agora quem não the quer mais sou eu'. Aí deixei ele e saí com uma mão na frente e outra atrás, sem nada! De duas empregadas que eu tinha na minha casa e um motorista, eu fui ser empregada doméstica na casa dos outros. Fui pela minha liberdade. Aí me senti gente!Quando eu comecei a trabalhar, mesmo os recursos não dando pra nada, coloquei um carrinho de cachorro quente pertinho da minha casa, comecei a trabalhar, ai comecei a me valorizar. Né que eu tenho valor! Né que eu sei fazer alguma coisa! Mesmo não sendo empresária, eu sei fazer alguma coisa. Ai começaram os horizontes a abrir, assim, comecei a trabalhar, e até hoje. (Rosália)

$\mathrm{Na}$ vida econômica, a violência não teve nenhuma conseqüência. Comecei a trabalhar em novembro e acho que foi mais por isso que eu decidi minha vida e não viver mais com ele, já que eu estava podendo trabalhar e sustentar meu filho, entendeu? Só assim também eu tive coragem de vir ate aqui, graças a Deus [...]. (Márcia).
Quando eu fui morar com ele eu não tinha nada e hoje eu tenho alguma coisa...porque agora eu já tenho forças pra me libertar e antes não. Antes ele dominava, eu me acovardava, ele dizia que quem mandava era ...e depois de tantos anos, chegou um dia que eu disse: 'Já que eu não sirvo pra você eu quero que você deixe esta casa' e ele disse : 'Eu não deixo' Ai eu disse 'Então você fica e saio eu, os incomodados, se retiram e você fica com a sua casa, com as suas coisas' Aí ele disse: 'Meu filho não vai' $\mathrm{E}$ eu: 'Você fica com seu filho também que depois eu vou na justiça e pego ele de volta' Eu só quero quem me quer, quem não me quer...sai de casa. (Vitória).

A violência é definida como uma relação de força caracterizada em um pólo pela dominação e no outro pela coisificação, que explicita a atitude de quem detém o domínio de anular o outro na sua condição de sujeito, ao submetê-lo a sua vontade ${ }^{(12)}$.

A exposição continuada a uma situação de violência pode realmente levar à inércia e passividade durante muito tempo, até que haja um movimento de busca de ajuda e ruptura do ciclo de dominação/submissão. A capacidade de reação, embora submersa, pode, a qualquer momento, aflorar como desejo de mudança (18). Portanto, nenhum homem ou mulher sofre passivamente as determinações históricas. Há sempre a possibilidade de reação para tornarse sujeito de sua história, como podemos observar nos depoimentos a seguir:

Não dá! Aí chega um dia em que você olha assim, e diz: 'O que é que eu estou fazendo aqui?'..(Vitória). 
Guedes RN, Silva ATMC, Coelho EAC. Violência conjugal: problematizando a opressão das mulheres vitimizadas sob olhar de gênero . Revista Eletrônica de Enfermagem [serial on line] 2007 Mai-Ago; 9(2): 362-378. Available from: URL: http://www.fen.ufg. br/revista/v9/n2/v9n2a06.htm

Quando foi há pouco tempo agora, eu fiquei pensando e decidi que não queria mais essa vida pra mim. Aí comecei a trabalhar. (Márcia).

Nesses depoimentos, as mulheres revelaram a descoberta da capacidade de trabalho como reação à dominação e caminho que thes possibilitou a independência financeira e libertação. A singularidade de cada mulher faz com que seja diferente seu modo de reação à condição de violência. Diferentemente dos depoimentos apresentados acima, Atena e Priscila, destituídas da condição de independência financeira por estarem fora do mercado de trabalho, revelam, em seus discursos, as limitações e dificuldades que permeiam a vida das mulheres que decidem abandonar a relação conjugal, quando dependem financeiramente do parceiro:

Eu vejo ele aí com tudo, tudo que ele tem construiu em cima de mim e hoje eu me vejo sem nada. Só tenho uma cama. Só não estou debaixo de uma ponte porque tenho a casa dos meus pais. Não posso pedir tudo a eles porque, eles não podem me dar. (Atena).

[...] eu não trabalho. Tá muito ruim. Eu dependo dele. (Priscila).

As análises qualitativas da posição das mulheres no espaço público do mercado de trabalho e privado das relações familiares constataram que as relações de gênero exacerbam as desigualdades associadas às classes sociais. A precariedade da situação social das mulheres passou a ser vista como resultante da divisão sexual do trabalho, de menores oportunidades em termos de educação, de situações de trabalho instáveis e com menor remuneração, de níveis inferiores de saúde e bem estar, de reduzida participação nas decisões (tanto no âmbito privado como no público, mais especialmente, nesse) e de limitada autonomia pessoal ${ }^{(19)}$.

Os discursos revelados nas falas de algumas participantes deste estudo demonstram que a independência financeira e o acesso ao mercado de trabalho, mesmo em ocupações consideradas subemprego, oferecem às mulheres maiores condições de conquista da autonomia e liberdade. Porém, a desigualdade de gênero ainda está presente, mesmo na vida dessas mulheres que obtiveram tais conquistas, como podemos observar nos depoimentos que seguem:

Estou pagando a casa, tô pagando água, tô pagando luz, tudo! Porque eu fiz um acordo com ele que eu ia ficar pagando isso pra ele até ele arrumar um emprego, porque eu não quero ver ninguém jogado. Então eu disse: 'Você fica aí já que eu tenho uma renda'. Já que ele não trabalha né? 'Então você fica aí...E você vai refazer sua vida' Só que ele não tá refazendo e acha que tem direito a mais alguma coisa.( Vitória)

Então essa chantagem emocional que ele fazia comigo que foi me acabando [...] Passava três dias fora de casa, essa coisa toda, e quando chegava em casa exigia tudo pronto. Como eu trabalhava ele exigia meu dinheiro, pra emplacamento de carro, de moto, mensalidade da casa, quando faltava alguma coisa eu tinha que ressarcir o dinheiro que ele tinha gastado. (Atena)

Os textos acima nos revelam que a independência financeira não é suficiente para possibilitar às mulheres relações de gênero mais igualitárias. Esse aspecto é confirmado em estudo anterior, no qual observamos que, mesmo quando as mulheres dispõem de condições econômicas para a superação da 
Guedes RN, Silva ATMC, Coelho EAC. Violência conjugal: problematizando a opressão das mulheres vitimizadas sob olhar de gênero. Revista Eletrônica de Enfermagem [serial on line] 2007 Mai-Ago; 9(2): 362-378. Available from: URL: http://www.fen.ufg. br/revista/v9/n2/v9n2a06.htm

desigualdade de gênero, elas não conseguem romper totalmente as amarras da subordinação, pois estas ocorrem por mecanismos ideológicos de reprodução do Status Quo que só serão superados na construção de novas relações sociais, o que requer a desconstrução daquilo que está posto hegemonicamente como atributos de mulheres e homens, na atualidade ${ }^{(20)}$.

As mulheres sujeitos dos discursos apresentados, ao terem sido entrevistadas em um momento em que denunciavam a violência conjugal às autoridades policiais, demonstraram ser pessoas que vivenciaram situações-limite de opressão masculina manifestada através da violência e do poder dos parceiros sobre o seu corpo, mente e com implicações sobre sua vida ou morte. $\mathrm{Na}$ violência física, perseguições e ameaças, que levaram essas mulheres a denúncia estão submersas outras formas de violência, consideradas mais sutis, porém que causam tantos danos à sua vida quanto à violência fisicamente manifestada.

Desse modo, a definição cultural do papel feminino, ao longo da história, cria, em nossa sociedade, espaços para o exercício da violência, exclusão e das desigualdades na vida das mulheres. Essa violência é manifestada, desde as situações cotidianas consideradas "normais", como a exclusão feminina dos espaços mais qualificados do mercado de trabalho e a negação de seus desejos e direitos sobre o seu corpo, até a violência física propriamente dita, que constitui apenas a "ponta de um icerbeg" constituído das diversas formas de opressão invisibilizadas por uma "naturalização" social da desigualdade entre os sexos que justifica e legitima as relações de poder e permitem a violência contra as mulheres no âmbito de suas relações conjugais.

\section{CONCLUSÕES}

Historicamente, as diferentes formações sociais e culturais instituíram certos valores éticos como padrão de comportamento e de relações sociais que oferecesse alguma segurança física e psíquica de seus membros, para, desse modo, conservar e/ou proteger o grupo social. As várias culturas atribuíram diferentes significados e conteúdos à violência, conforme os valores de cada época e lugar. Contudo, alguns aspectos da violência são percebidos em suas semelhanças, nas várias culturas e sociedade, como pano de fundo contra o qual os significados da ética são construídos, como valores positivos ou barreiras éticas.

A violência contra a mulher pode ser explicada como um fenômeno que se constitui a partir da naturalização da desigualdade entre os sexos, que se assenta nas categorias hierárquicas, historicamente construídas como um dos mecanismos ideológicos, capaz de legitimar o status quo, entre os quais se encontram as classificações sociais e, aqui, a classificação sexual.

A classificação sexual permite que uma das partes do contrato conjugal exerça a dominação sobre a outra parte. Na dominação entre os sexos, na cultura, sobretudo latinoamericana, o sexo masculino exerce a dominação física e psíquica, com legitimidade social. Essa dominação, a princípio imposta pela maior força física, é ampliada para as dimensões psicológicas e tem o reconhecimento cultural manifesto no respeito 
Guedes RN, Silva ATMC, Coelho EAC. Violência conjugal: problematizando a opressão das mulheres vitimizadas sob olhar de gênero. Revista Eletrônica de Enfermagem [serial on line] 2007 Mai-Ago; 9(2): 362-378. Available from: URL: http://www.fen.ufg. br/revista/v9/n2/v9n2a06.htm

ao espaço privado das relações conjugais que se expressa até nos provérbios populares, como o que afirma: "Em vida de marido e mulher, ninguém deve meter a colher". Contudo, essa dominação inferioriza as mulheres desqualificando o "outro" da relação como algo "natural" e insuperavelmente inferior, porque biologicamente diferente.

Em oposição a essa racionalidade, a abordagem de gênero tem permitido, aos pesquisadores, enfrentar o desafio de repensar as desigualdades nas relações produzidas entre os sexos à luz da produção e reprodução dos diferentes contextos sociais e históricos, nos quais a submissão e a desigualdade contribuem para a manutenção do status quo que atende aos interesses dos grupos hegemônicos. Todavia, o palco da submissão feminina é também um campo de luta para o reconhecimento de seu estatuto de sujeito de sua história ao lado dos homens e não apenas de conformismo com a condição de sujeito sujeitado que tem o significado identificado com um objeto. Nessa perspectiva, a violência contra a mulher reproduz um fenômeno que acontece na sociedade mais ampla que é a violência da dominação de classes sociais, explicada como algo natural, racional e legal a partir de um estilo de pensamento ou ideologia que invisibiliza o processo de constituição da violência, primeiro no âmbito do espaço público.

No âmbito do espaço privado, esse mecanismo ideológico se traduz na violência doméstica, como uma de suas formas, e, contra as mulheres, ele é subentendido como "destino" que só pode ser enfrentado no contra-discurso, na oposição do determinismo que o enfoque de gênero e o âmbito da saúde permite ao identificar a necessidade do resgate da produção de uma necessidade para as mulheres oprimidas, a necessidade de liberdade como condição imprescindível para sua existência civil, biológica, psicológica e social.

Nesse sentido, a violência contra a mulher, não apenas a violência física é algo que não se revela, à primeira vista, porque se reveste de significados subjetivos, sobretudo porque, como mecanismo ideológico, parece não estar diretamente ligado a vontade humana, mas ligado a uma "natureza" que impossibilita a transformação do fenômeno. Contudo, o exame do problema tem revelado que a igualdade humana, bem como a desigualdade são construções sociais e humanas que podem ser transformadas e que, por seu alto teor qualitativo, fazem parecer algo que não pode ser mudado.

A fase qualitativa deste estudo demonstra, através dos depoimentos das mulheres em situação de violência, que a violência conjugal é uma forma de manifestação da assimetria de poder presente nas relações de gênero, sendo esse poder construído e legitimado historicamente pela sociedade patriarcal, que utiliza o argumento de maior capacidade física e intelectual masculina para justificar sua superioridade, alimentando a opressão feminina. Os discursos das participantes revelaram o reconhecimento, pelas mulheres, do poder masculino sobre elas, refletido pelo temor e pela subordinação na relação conjugal em que ocorre a violência.

Isso confirma que a ideologia patriarcal da sujeição natural feminina é introjetada por toda a sociedade, inclusive pelas mulheres, que temem a superioridade da força física do 
Guedes RN, Silva ATMC, Coelho EAC. Violência conjugal: problematizando a opressão das mulheres vitimizadas sob olhar de gênero . Revista Eletrônica de Enfermagem [serial on line] 2007 Mai-Ago; 9(2): 362-378. Available from: URL: http://www.fen.ufg.br/revista/v9/n2/v9n2a06.htm

parceiro, manifestada através da violência. Os discursos revelaram o controle total do homem sobre a vida e a vontade das mulheres. Esse domínio corresponde a uma espécie de tutela construída e legitimada pela cultura machista, necessária para administrar os excessos de paixões, nesse enfoque, que fazem parte da imperfeição da natureza feminina.

A conquista da independência financeira e do trabalho no mundo público revelou-se, em alguns depoimentos, como fator de transformação e libertação na vida das mulheres vítimas de violência conjugal. Depoimentos de mulheres dependentes financeiramente do cônjuge revelaram as dificuldades de enfrentamento da situação de opressão, assim como do seu restabelecimento após o abandono da relação. Podemos, então, confirmar que a independência financeira possibilita, às mulheres, maiores condições objetivas de superação das desigualdades de gênero, porém não as liberta totalmente dessas amarras, uma vez que essa libertação requer a construção de novas relações sociais, o que implica a desconstrução do que está posto hegemonicamente como relação de gênero, em nossa sociedade.

Finalmente, no sentido de contribuir para repensar o modo de cuidar da mulher em situação de violência doméstica, é importante que os profissionais que lidam com essas mulheres produzam novas categorias e apropriem-se das já existentes nas diversas áreas do conhecimento, sobretudo nas ciências sociais, para que o princípio da integralidade da assistência à saúde do SUS possa ser um produto que possa ser alcançado, também, pelas mulheres vítimas de violência doméstica. Isso significa pensar o cuidado em saúde, não apenas como aplicação de um saber instrumental ou técnico especializado da razão tecnológica instrumental hegemônica, que não permite uma compreensão do fenômeno, mas, uma explicação limitada do processo de viver, adoecer e morrer.

A possibilidade de um cuidado de saúde ampliado para as mulheres em situação de violência conjugal implica considerar a saúdedoença como um processo dinâmico relacionado aos diferentes universos de significação, além da valorização de qualidades como solidariedade, confiança, transformação dos valores hegemonicamente defendidos, relações sociais igualitárias e reconhecimento das diferenças, para que as práticas profissionais possam ser instrumentos com possibilidades de contribuir para a emancipação social.

\section{REFERÊNCI AS}

1. Organização Panamericana de Saúde. Informe mundial sobre la violência y la salud: resumem. Organizacion Mundial de la Salud, Washington, DC; 2002.

2.Gomes R, Minayo MCS, Silva CFR.Violência contra a mulher: uma questão transcultural e transnacional das relações de gênero. In: BRASIL, Ministério da Saúde. Impacto da violência na saúde dos brasileiros. Brasília (DF); 2005. p.118-140.

3. Ferreira VC. Relações sociais de sexo e segregação do emprego: uma análise da feminização do escritório em Portugal. [Doutorado] Coimbra. Faculdade de Economia / Universidade de Coimbra; 2003.

4. Guedes RN. Violência conjugal: problematizando a opressão das mulheres vitimizadas sob olhar de gênero. [Dissertação] João Pessoa (Pb) PPGEnf/CCS/ Universidade Federal da Paraíba; 2006.

5. Heise L, Pitanguy J, Germain A. Violencia contra la mujer: la carga oculta sobre la salud. Organização Panamericana de la Salud. Programa Mujer, Salud y Desarrollo. Washington, DC; 1994. 
Guedes RN, Silva ATMC, Coelho EAC. Violência conjugal: problematizando a opressão das mulheres vitimizadas sob olhar de gênero . Revista Eletrônica de Enfermagem [serial on line] 2007 Mai-Ago; 9(2): 362-378. Available from: URL: http://www.fen.ufg. br/revista/v9/n2/v9n2a06. htm

6. Heise L. Gender-based abuse: the global epidemic. Cad. Saúde Pública. [serial on line] 1994. [cited 2006 May 5]; 10(supl. 1): 135145. Available from: URL: http://www.scielo.br/pdf/csp/v10s1/v10supl1a 09.pdf

7. Barbosa MA, Medeiros M, Prad, MA; Bachion MM, Brasil VV. Reflexões sobre o trabalho do enfermeiro em saúde coletiva. Revista Eletrônica de Enfermagem [serial on line] 2004 jan-abr [cited 2006 Jun 02]; 6(1): 9-15. Available from: URL: http://www.fen.ufg.br/revista/revista6_1/f1_co letiva.html

8. Fiorin J L. Linguagem e ideologia. $6^{a}$ edição. São Paulo (SP): Ática; 1998.

9. Pateman C. O contrato sexual. São Paulo (SP): Paz e Terra; 1993

10. Silva ATMC. A reforma psiquiátrica em João Pessoa-PB: limites e possibilidades de transformação do trabalho para produzir saúde mental. [Doutorado] São Paulo (SP): Escola de Enfermagem da Universidade de São Paulo; 2003.

11. Lowy M. Ideologias e Ciência Social. São Paulo (SP): Editora Cortez; 1985

12. Chauí M. Cultura e democracia: o discurso competente e outras falas. São Paulo (SP): Moderna; 2006.

13. Pitangui J. Gênero, violência e Direitos Humanos. In: Ministério da Saúde (BR). Revista promoção da saúde. ano 03 n. 06. Brasília (DF); 2002 p.67-70

14. Dantas-berguer SM, Giffin K. A violência nas relações de conjugalidade: invisibilidade e banalização da violência sexual?. Cad de saúde pública, mar-abr. Rio de Janeiro (RJ); 2005, v.21, n.2, ISSN 0102-311X. p.417-425.

15. Santos BS. A construção multicultural da igualdade e da diferença. N.135, 1999. Coimbra: Oficina do CES .Centro de Estudos Sociais; 1999.

16. Vasconcelos CMCB, Prado ML. Vivendo o sofrimento e os desafios no trabalho: expressões autocríticas de um grupo de enfermeiros educadores. Revista Eletrônica de Enfermagem [serial on line] 2004 jan-abr [cited 2006 abr 26]; 6(1): 47-58. Available from:

URL:

http://www.fen.ufg.br/revista/revista6_ 1/pdf/f 5_desafios.pdf

17. Giffin K. Pobreza, desigualdade e eqüidade em saúde: considerações a partir de uma perspectiva de gênero transversal. Cad. Saúde Pública. [serial on line] 2002. [cited 2006 jul 06]; 18 (supl.): 103-112. Available from: URL: http://www.scielo.br/pdf/csp/v18s0/13797.pdf
18. Araújo MF. Violência Conjugal: uma proposta de intervenção com casais. In: FeresCarneiro T, editor. Família e casal: arranjos e demandas contemporâneas. Rio de Janeiro (RJ): PUC-Rio/ Edições Loyola; 2003. p.185199.

19 Fonseca RMGS. Equidade de gênero e saúde das mulheres. Revista da Escola de Enfermagem da USP, São Paulo, v. 39 . p.450459; 2005. Suplemento 4.

20. Guedes RN. Problematizando a vida e o trabalho de mulheres profissionais do cuidado em saúde. [Trabalho de conclusão de curso.] Enfermagem/ Universidade Federal da Paraíba. J oão Pessoa $(\mathrm{Pb}) ; 2004$.

Artigo recebido em 29.11.06

Aprovado para publicação em 27.08.07 